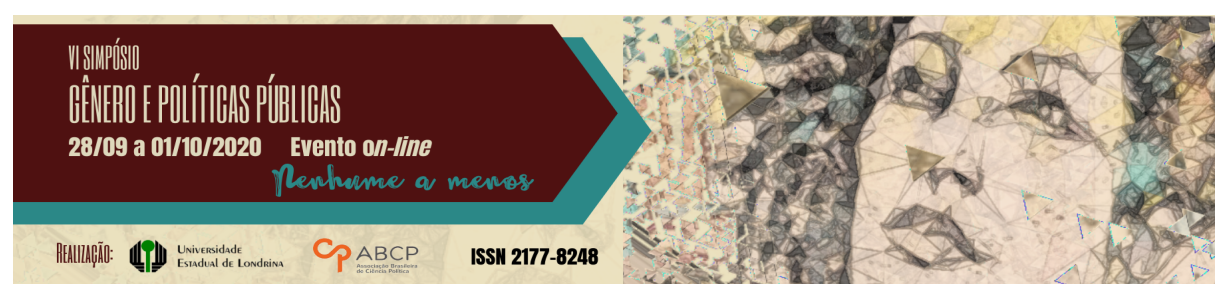

\title{
Versando identidade e negritude
}

\section{Alessandra Guimarães dos Santos Medina ${ }^{1}$ Wânia Rezende ${ }^{2}$}

\section{Resumo}

Este trabalho tem a finalidade de pensar a categoria da identidade, considerando aspectos da nacionalidade e, também enquanto identidades que refletem determinados grupos sociais, nesse caso, meninas e meninos de ancestralidade negra.Para isso será feito uma pesquisa bibliográfica acerca da categoria de identidade. Além disso,na tentativa de aferir aspectos sobre a formação da identidade esta pesquisa tem a propositura de apresentar uma análise sobre aspectos culturais marcados pelo consumo, considerando o tecido social que compõe nossa sociedade. Para isso, foi realizada a técnica de Grupo Focal com jovens estudantes do Ensino Médio, da rede estadual pública do município de Mandaguari. Essa pesquisa pretende elencar a relevância e contribuições, das relações sociais estabelecidas no espaço escolar para o constructo de formação das identidades, notoriamente atravessada pelo consumo.

Palavras-chave: identidade; consumo; racismo.

\section{Versus identity and blackness}

\section{Abstract}

This work has the purpose of thinking about the identity category, considering aspects of nationality and, also as identities that reflect certain social groups, in this case, girls and boys of black ancestry. For this, a bibliographic research about the identity category will be done. In addition, in

1 Mestranda Programa de Ciências Sociais Universidade Estadual de Maringá. agsmedina8@gmail.com.

2 Professora Doutora Programa de Ciências Sociais Universidade Estadual Maringá. waniasilva@yahoo.com

GT 09 - Gênero e relações étnico-raciais: as desigualdades e os desafios contemporâneos 
an attempt to assess aspects of identity formation, this research proposes to present an analysis of cultural aspects marked by consumption, considering the social fabric that makes up our society. For this, the Focal Group technique was carried out with young high school students, from the public state network of the municipality of Mandaguari. This research intends to list the relevance and contributions, of the social relations established in the school space for the construct of identity formation, notoriously crossed by consumption.

Keywords: ideny; consumption; racismo.

\section{Introdução}

Olhando para a situação da nossa conjuntura social, nota-se urgência em reflexões demandadas da necessidade de atender e entender a diversidade. $E$ isso nos leva a primordial ação humanizadora de enfatizar um processo de escolarização que considere os sujeitos envolvidos em suas especificidades, sobretudo àquelas que, por vezes, possa subjugar à condição de discriminação como por exemplo o racismo vivenciado pelo povo negro, que muitas vezes pode até ser lido, perversamente como racismo recreativo devido a estrutura racista como nos ensina Adilson Moreira:

Em uma ocasião recente, muitos foliões e foliãs se fantasiaram de negros em uma conhecida cidade turística. Pintaram a cara de preto, vestiram perucas com cabelo crespo e acentuaram seus narizes, bocas e nádegas para se aproximarem da figura estereotipada de uma pessoa negra. Alguns desses homens brancos e algumas dessas mulheres brancas reproduziam trejeitos que para eles correspondem à forma como pessoas negras se comportam. Alguns faziam gestos tresloucados ou imitava pessoas bêbadas para retratar homens negros, e outros assediavam homens brancos para representar a suposta sexualidade exacerbada da mulher negra. Fotos e vídeo foram divulgados nas redes sociais e os foliões sofreram críticas severas. Os que protestaram afirmaram que a negritude não é uma fantasia de carnaval; também disseram que os 
trejeitos reproduzidos são estereótipos raciais derrogatórios, razão pela qual comportamentos como esses nunca deveriam ocorrer. Várias pessoas brancas reagiram a esses comentários imediatamente. Elas afirmaram que eles, os foliões, estavam simplesmente representando personagens fictícios, motivo pelo qual não havia qualquer tipo de ofensa racial envolvida. Esses indivíduos alegaram que os foliões brancos estavam apenas se divertindo; eles não tinham nenhuma intenção de ofender negros. Alguns falaram que essa prática poderia até mesmo ser vista como uma forma de homenagem a pessoas negras (MOREIRA, 2019 p. 18).

Este assunto emergiu durante as aulas de Cultura, Consumo e sociabilidade, em meio as leituras e discussões, surgiu a inquietação para um aprofundamento sobre a relação cultural, sobretudo numa sociedade atravessada pelo consumismo, e principalmente como tudo isso afeta a identidade da pessoa negra, numa perspectiva macro e na identidade singular. Essa inquietação decorre sobretudo da leitura do texto Cultura negra e educação de Nilma Lino Gomes, pois não se trata de um simples " elogio das diferenças" mas sim da "variabilidade de formas de conceber o mundo, às particularidades e semelhanças construídas pelos seres humanos ao longo do processo histórico e social". Gomes (2003) tem um recorte racial que considera os cabelos como marca de identidade, entre o povo negro. Sabe-se que "no início do século XV o cabelo funcionava como um condutor de mensagens na maioria das sociedades africanas ocidentais. Muitos integrantes dessas sociedades, incluindo os Wolof, Mende, Mandingo e Iorubás, foram escravizados e trazidos para o Novo Mundo". Diante disso, seria possível afirmar que ao percebemos as cabeças de nossos jovens, marcadamente pelas ascendência negra,seja pelo uso do turbante, das tiaras, dos penteados afro centrados ou pelos lindo e estilosos, negramente esplendorosos Black powers estamos diante de um fortalecimento da Identidade do Povo Negro? Para pensar sobre isso, é necessário, algumas considerações acerca da perspectiva do 
reconhecimento das identidades, considerando que essa tem sido reincidentemente umas das reflexões das ciências sociais nas últimos tempos, sobretudo nesses tempos, em que estamos atolados.

De acordo com Lopes (2002) pensar a categoria identidade requer que considere-se "a vida dos homens em sociedade, segundo direitos, religiões, costumes, estruturas sociais e mentalidades" Por isso esse trabalho exige que se trate de elemento indispensáveis ao processo identitário como, por exemplo, o processo escolar e a demanda que surge nas relações sociais deste contexto e, como tudo isso perpassa no reconhecimento, fortalecimento ou esvaziamento das identidades. A disciplina Cultura consumo e sociabilidade, marca de forma contundente a trajetória da vida social pois suscita a pesquisa de categorias, e aprofundamentos etimólogos que joguem luz na reflexões sobre identidade. $\mathrm{O}$ que está em jogo quando falamos em Identidade Nacional, que lugar tem o povo negro nesse constructo? Pois bem, para o desenvolvimento desse estudo será indispensável uma pesquisa bibliográfica tratando de categorias como identidade, povo negro, racismo, cultura e consumo. E para além disso, como o propósito não se limita a uma revisão literária, a metodologia se nessa pesquisa, se valerá também da aplicação de um Grupo Focal, com jovens estudantes do Ensino Médio, da rede Estadual de Educação, do município de Mandaguari. Todos os jovens tem marcadamente ascendência negra. O Grupo Focal, de acordo com Gondim (2003) é uma "técnica de investigação qualitativa comprometida com a abordagem metacientífica compreensivista, analisando ainda a questão dos fatores que afetam o processo de discussão dos grupos focais e, em consequência, a validade de seus resultados, apontada como um dos maiores desafios metodológicos da referida técnica" . Portanto esta será uma sessão muito interessante deste trabalho.

Numa abordagem qualitativa esse trabalho tem como "menina dos olhos" o desenvolvimento e análise da dinâmica do Grupo Focal, na busca de elencar aspectos comuns que perpassam nas identidades dos jovens, tendo como direcionamentos elementos da composição do 
tecido social, como feminicídeo, racismo e os debate sobre relacionamentos no contexto escolar. Feito isso, é possível preponderar, a respeito das noções positivas ou negativas do reconhecimento das identidades?

Para esse fim o diálogo será feito com base textos estudados durante as aulas, Marcel Mauss, Lívia Barbosa e Colin Campbel. Na perspectiva de fazer essa pesquisa com uma leve abordagem na identidade da pessoa negra, a base de leitura são as narrativas Nilma Lino Gomes Suelli Carneiro e Conceição Evaristo.

Ao realizar este trabalho, além da perspectiva das ciências sociais, serão levados em consideração alguns elementos da Educação, dada a formação e atuação profissional na educação básica, a mais de vinte anos, isso certamente contaminará os trabalhos que certamente será marcado pelo viés da Pedagogia. Nesse sentido, é interessante registra um destaque que Candau e Oliveira (2010) fazem respeito de um importante direcionamento dado nos PCNs( Parâmetros Curriculares Nacionais) da década de 1990, "a construção da noção de identidade, relacionando identidades individuais, sociais e coletivas e propondo a apresentação de outros sujeitos históricos diferentes daqueles que dominaram o ensino dessa área curricular no Brasil."

\section{Uma questão de identidade}

Ao pensar a categoria identidade, de acordo com Lopes (2002) sabe-se que há estudos que se preocupam com essa categoria desde os tempos histórico social na Pré-História, e se faz isso com base em estudos de Marcel Mauss (1974), “o autor analisa a caracterização da pessoa como definição social da personagem nas sociedades primitivas para, a seguir, construir uma história social da noção, no Ocidente."

Porém sem demérito, aliás, destacando a devida importância para esse resgate reflexivo do processo histórico social, o recorte deste trabalho permite que se faça uma abordagem mais e contextualizada 
para que se chega ao propósito estabelecido.

Dessa forma entende-se já de inicio que pensar identidades significa pensar laços, questões de continuidade que estão para além de simples cotidiano, trivial, e sobretudo pensar identidade está para além de meras transposições ou alinhamentos perceptíveis por expressões culturais como por exemplo, padrões de consumo, conforme Vitor Menezes:

Pensar em identidade, ou identidades, significa refletir sobre os laços intra e extra grupos, o processo de definição de pertencimento e diferença, a produção simbólica e material de fronteiras. Dessa forma, as ciências sociais apresentam a noção de identidade, assim como o processo de identificação, como um dos grandes focos de análise e debate. (MENEZES, 2014, 69).

A identidade é formada por elementos simbólicos e sociais, portanto, nesta perspectiva soa um tanto negativo a possibilidade uniformidade identitária ou uma identidade nacional, já que tem-se como principio básico para constituição da categoria identidade é diversidade e individualidade, "a identidade e a diferença são construções sociais e culturais resultados de atos de criação linguística, sendo que as identidades necessitam ser nomeadas, argumentadas, instituídas por meio de atos de fala, em uma relação dialógica entre simbólico e social "(MENEZES, 2014, 70) Portanto pensar sobre identidade requer considerar aspecto macro de uma sociedade, mas sobretudo demanda pensar aspectos anteriores a própria pessoa, assim sendo a ancestralidade importa para a identidade.

\section{Sobre o Grupo Focal}

Este trabalho tem propósito e justifica-se pela contribuição para que os membros de fato, possam pensar e posicionar a cerca dos tensões percebidas, na execução dos encontros previamente sistematizados para equipe, bem como as impressões captadas no 
interior da escola que contribuem para investigação que propomos.

Os grupos focais são grupos de discussão que dialogam sobre um tema em particular, ao receberem estímulos apropriados para o debate. Essa técnica distingue-se por suas características próprias, principalmente pelo processo de interação grupal, que é uma resultante da procura de dados. Em uma vivência de aproximação, permite que o processo de interação grupal se desenvolva, favorecendo trocas, descobertas e participações comprometidas. É também motivo de nossa escolha o GF porque proporciona descontração aos participantes para que possam responder as questões em grupo, e não apenas respondendo um questionário com respostas muitas vezes mecânicas e engessadas.

Além disso, o GF permite ao pesquisador um exercício que esta para além de examinar as diferentes análises das pessoas em relação ao tema. É possível também explorar como os fatos são articulados, censurados, confrontados e alterados por meio da interação grupal e, ainda, como isto se relaciona à comunicação de pares e às normas grupais.

Isto nos ajudará a inferir sobre o que chamamos de cultura escolar e as práticas pedagógicas escolhidas para o tratamento das questões sobre diversidade na escola e a impressão desse processo na identidade ou na noção de identidade apresentada no G.F. O grupo focal é um instrumento valioso para a pesquisa qualitativa, pois conforme Gondim $(2013, p, 152)$ G. F. serve à varias finalidades, tudo depende do objetivo de quem pesquisa, podendo ser : "forma de reunir informações necessárias para a tomada de decisão; outros os vêem como promotores da auto-reflexão e da transformação social e há aqueles que os interpretam como uma técnica para a exploração de um tema pouco conhecido, visando o delineamento de pesquisas futuras."

A experiência de um grupo focal, proporciona oportunidade riquíssima para se analisar aspectos preponderantes sobre um determinado grupo de relações sociais. Muitas vezes o grupo 
corresponde as primeira hipóteses aventadas pelo pesquisador, mas as vezes pode surpreender pelas narrativas que surgem desse encontro de palavras que seguem um certo itinerário preestabelecido pelo condutor da dinâmica.

\section{Considerações relevantes sobre o desenvolvimento do Grupo Focal e os meandros do racismo}

O grupo foi formado por quatro jovens adolescentes, sendo três meninas e um menino, com idade entre dezesseis e dezenove anos, todos estudantes do Ensino Médio da rede Estadual de Ensino do Paraná. Todos tiveram toda a trajetória escolar feita na rede pública.

A conversa teve inicio com a apresentação da proposta, o tema do trabalho e objetivo da encontro, bem como sua relevância para a pesquisa científica. Quem deu início foi o J. P. o único menino, teria outro, mas na última hora ficou encabulado e não foi. J. P. está cursando a primeira série do Ensino Médio, no período vespertino. $\mathrm{Na}$ sequência foi M. E. quinze anos, segundo ano do Ensino Médio, no período da manhã. J.P. e M. E. estudam no mesmo Colégio, Em seguida foi $\mathrm{M}$. A. de uma jovem de dezenove anos, a única do grupo que já tem trabalho com carteira assinada, está com matrícula trancada no primeiro ano do Ensino Médio, pretende retornar e concluir essa etapa da Educação Básica, neste ano, pois vê a necessidade para promoção no emprego. Depois foi A. D. de dezoito anos, estudante do segundo ano do Ensino Médio, no período noturno, pretende concluir o Ensino Médio. O primeiro tema lançado aop grupo foi referente a vida na sociedade na sociedade de consumo, qual era o consumo em comum entre eles e, a resposta foi uníssona Consumo da essência de Narguilé. Sobre o que deixa esse hábito se importante entre eles é que para além da sensação palatal, perceptível pela essência utilizada no carvão, o grupo destaca que o momento favorece conversas desabafos e que geralmente nesse momento, geralmente, não fazem uso do celular. Ainda pontuam que sabem dos riscos à saúde, mas escolhem 
desfrutar desse consumo, que de certa deforma marca a identificação desses jovens.

Em relação ao processo de escolarização reconhecem a importância para alcançarem seus objetivos, enxergam na escola a possibilidade deformação para exercício da profissão escolhida. Elencam que com certa freqüência presenciam situações de descriminação e racismo na escola. Inclusive teve uma participante que recordou as series iniciais, quando alguns colegas de classe tiravam sarro do cabelo, da cor, do nariz e ela ficava muito triste. E após ouvirem o relato todos concordam que tem que denunciar o racismo, fazer boletim de ocorrência... Ao serem indagados sobre situações de racismo, consideram racismo os de xingamentos e as situações onde "há sarros" por conta do cabelo.... Em relação a isso, explicita-se a necessidade se reconhecer e valorizar as identidades nacionais, por esse motivo:

O debate sobre as relações raciais no Brasil não deve ser entendido como tem de interesse exclusivo de parcelas restritas da população. $\mathrm{Na}$ verdade, esse assunto não pode ser considerado nem um problema negro( que os levaria a ver esta parcela da população como um problema ser superado) e nem como um exclusivo problema do negro(que nos levaria a entender que o assunto preocupa apenas este contingente).O mesmo entendimento aplica-se quando pensamos nas demandas sociais indígenas. O tema das relações raciais e, mais especificamente, da promoção da igualdade racial deve ser compreendido no interior de um marco holístico em que todos os contingentes da população estão convocados a dar seu testemunho. Os problemas que afetam negros e negras são produzidos por meio da ação daqueles que são, ou julgam que são, brancos e que adotam práticas de discriminação de afrodescendentes contra 
pessoas de seu mesmo grupo devem ser pensadas como produtos de uma sociedade pautada pelos valores culturais, morais, e estéticos portados por pessoas de ele clara e de ascendências européia. As pronunciadas desigualdades raciais existentes no Brasil não formam um problema único dos grupos desfavorecidos, pois essas disparidades representam uma perda para toda nação, mesmo para os integrantes do grupo discriminador, que se tornam limitados do ponto de vista humanístico, moral, cultural e, sob certa perspectiva, até mesmo econômico. (PAIXÃO, 2006, 15).

A respeito dos estilosos cabelos, penteados, indumentárias que remetem a identidade africana, consideram de forma categórica que tudo não passa de moda, que tudo isso é questão de tempo, para terem outra forma de se vestirem adornarem ou pentearem os cabelos, mas que tudo isso se deve ao fato de as pessoas estarem estudando e vendo que em "África, não tem só coisa feia" Vemos portanto com a questão do consumo marca o processo de identidade, nesse sentido Barbosa e Campbell (2006, p.21) “o consumo pode ser visto como alienação, falta ou perda de autenticidade, mas também pode ser visto fonte de criatividade e, autoexpressão, e identidade."

Sobre o feminicídeo as ideias divergem um pouco, mas todos concordam que o crime é inaceitável. Para M.E. as coisas vão ser sempre assim, "pode fazer o que quiser, nunca vai mudar" Para J.P. não deveria ser dessa forma, a sociedade é injusta, porém reconhece" os carinha dão bebida pras mina, aí já viu, né..." O grupo entra em discussão nesse momento, justamente por conta dessa cultura machista, de estupro, que se vale da violência contra uma mulher num momento em que ela está vulnerável. Para M.A. muitas vezes a mulher até provoca o homem e depois joga a culpa cai só em cima do homem, "tem que ser ouvida as duas partes". A ausência de um discurso um pouco mais feminista, causou estranheza, que houvesse, por questões 
de identidade, um consenso sobre esse tema tão recorrente e absurdo em nossa sociedade que é a violência contra as mulheres.Mas não, o grupo demonstra, que a formação identitária, que tem tudo haver com o processo de escolarização, é ainda perpassada por uma educação patriarcal e machista. Como se aferiu nesse debate. Nesse sentido Suelli Carneiro (2003) estava coberta de razão quando escreveu que

o feminismo esteve, também, por longo tempo, prisioneiro da visão eurocêntrica e universalizante das mulheres. A conseqüência disso foi a incapacidade de reconhecer as diferenças e desigualdades presentes no universo feminino, a despeito da identidade biológica. Dessa forma, as vozes silenciadas e os corpos estigmatizados de mulheres vítimas de outras formas de opressão além do sexismo, continuaram no silêncio e na invisibilidade (CARNEIRO, 2003, p.118).

Com frequência, nesses últimos meses temos assistido pelos meios midiáticos eventos cotidianos que reverberam o racismo e o feminicídeo em nossa sociedade. Por isso é fundamental nos debruçarmos em estudo que pretendendo apontar possiblidades para que as implicações da nossa prática pedagógica possam rumar para ações que de celebre a diversidade, e o fortalecimento identitário corroborando deste maneira para que se tenha a noção de sua resistência e importância em continuar o movimento demandado por aqueles que foram minorizados ao longo do projeto de modernização.

\section{Palavras finais}

Esse trabalho está bem próximo do que nos ensina Conceição Evaristo, de uma escrevivência pois é carregado de simbolismo e sinceridade, posto que de fato é fruto de inquietação demandada durante as aulas da Professora Wânia, no entanto, para além disso, o trabalho não foi apenas cumprimento de uma exigência acadêmica, 
teve o propósito de pensar a identidade tendo como recorte a questão racial, com ênfase nas relações sociais no contexto escolar. E ainda havia a intenção de algumas possíveis proposituras para que a prática pedagógica possa rumar para educação que se efetive através da compreensão que as diferenças, mesmo aquelas que nos apresentam como as mais físicas, biológicas e visíveis a olho nu, são construídas, inventadas pela cultura. A natureza é interpretada pela cultura. Ao pensarmos dessa forma, entramos nos domínios do simbólico. É nesse campo que foram construídas as diferenças étnico/raciais. (GOMES, 2003)

Essa compreensão é indispensável a uma prática pedagógica para a valorização e fortalecimento de identidades, considerando o aspecto multicultural na formação do povo brasileiro.

Porém não se pode negar a fundamental necessidade de resgate e valorização da cultura do povo africano, uma vez que a diáspora africana contou com o projeto de genocídio e de epistemicídeo. Nesse sentido Grosfoguel (2016) isso foi possível devido ao privilégio epistêmico fruto de um projeto imperialista/ colonial/ patriarcal, que tem como premissa da inferioridade dos conhecimentos produzidos fora do eixo Europa e Estados Unidos. Portanto de um lado há o privilégio epistêmico, por outro há a inferioridade epistêmica. Ou seja o lugar do não conhecimento, em detrimento do superior produzido por homens ocidentalizados dos cinco países, que formam o cânone do pensamento nas humanidades e nas ciências sociais, que estrutura todo o mundo moderno. E isso interfere na noção identidade de um povo.

Portanto face ao contexto escolar e sua relevância positiva para formação das identidades brasileiras e,o devido reconhecimento da identidade do povo negro em solo brasileiro só será possível mediante resgate histórico, como propõe a Lei 10639/03, sendo efetivada de forma efetiva com práticas pedagógicas que possam, por exemplo, dirimir uma narrativa enfatizando a transmodernidade, um projeto global compartilhado contra o capitalismo, o patriarcado, o 
imperialismo e colonialismo. Que tenha como ponto de partida aquilo que, ao longo do tempo da construção histórica e social, foi descartado desvalorizado e julgado como inútil entre as culturas globais que privilegia apenas um tipo de saber, o eurocêntrico. E portanto negritude deve ser entendida como reconhecimento da ancestralidade e o espaço escolar deve favorecer essa ressignificação para os jovens negros.

É preciso dar evidência ao pluralismo, que compõe a histórias da Humanidade.

E sinceramente, em tempos como esses que temos vivido, onde o apelo da estrutura colonizadora, conservadora, racista, e machista está em voga em muitos lugares do mundo, mas sobretudo no nosso Brasil, decolonizemo-nos, aquilombemo-nos.

Se o preto de alma branca pra você É o exemplo da dignidade

Não nos ajuda, só nos faz sofrer Nem resgata nossa identidade Jorge Aragão

\section{Referências}

BARBOSA, Lívia; CAMPBELL Colin. Cultura, consumo e identidade. Editora FGV, Rio de Janeiro, 2006.

CANDAU, Vera Maria Ferrão; OLIVEIRA, Luiz Fernandes de. Pedagogia Decolonial e Educação Antirracista e Intercultural no Brasil.. Educação em Revista, Belo Horizonte, v. 26, n. 01, p.15-40, abr. 2010

CARNEIRO, Suelli. Mulheres em movimento. Estudos Avançados, 17, 49, 2003.

CARNEIRO, Suelli. Racismo e sexismo e desigualdade. São Paulo: Selo Negro, 2011. 
DOURADO, Pereira da Costa Simone. O uso de grupos focais na pesquisa sobre participação política. Caxambu, outubro de 2016 Disnponível em: https://www.anpocs.com/index.php/papers-40encontro/st-10/st16-7/10302-o-uso-de-grupos-focais-na-pesquisasobre-participacao- politica/file. Acesso em: 14 ago. 2019.

GOMES, Nilma Lino. Cultura Negra e Educação. Revista Brasileira de Educação, n. 23, 20003.

GONDIM, Sônia Maria Guedes. Grupos Focais como técnica de investigação qualitativa: desafios metodolégicos. Paidéia, 12, 24, p. 149-161, 2003.

GROSFOGUEL, R. A estrutura do conhecimento nas universidades ocidentalizadas: racismo/sexismo epistêmico e os quatro genocídios/epistemicídios do longo século XVI. Soc. estado., Brasília, v. 31, n. 1, p. 25-49, 2016.

LOPES, José Rogério. Os Caminhos da Identidade nas Ciências Sociais e Suas Metamorfoses na Psicologia Social. Psicologia E Sociedade, v. 14, n. 1, p. 7-27, jan./jun. 2002.

MENEZES, Vitor. Identidade e processos de identificação: um apanhado teórico. Revista Intratextos, v. 6, n. 1, p. 68-81, 2014.

MOREIRA, Adilson. Racismo Recreativo. São Paulo, Pólen, 2019. 